\title{
Relationship between Organizational Citizenship \\ Behavior \& Counterproductive Work Behavior in the Geographical Context of Pakistan
}

\author{
Zirgham ullah Bukhari \\ E-mail: zirgham.ullah.bukhari@gmail.com \\ Umair Ali \\ Faculty of Business Administration and Management Sciences \\ Army Public College of Management Sciences, Rawalpindi, Pakistan \\ E-mail: softheart_602@yahoo.com
}

\begin{abstract}
The study is focused on measuring Organizational Citizenship Behavior (OCB) and Counterproductive Behavior (CWB) in the Corporate Sector of Pakistan. Also this study focuses on measuring the relationship between the prior mentioned behaviors. As per previous studies we have hypothesized a converse relationship between the Counterproductive Behavior (CWB) and Organizational Citizenship Behavior (OCB). Results prove CWB has significant negative relationship with OCB. This study is being carried out to invoke Organizational Citizenship Behavior (OCB) along with reduction in CWB in Pakistani organizations.
\end{abstract}

Keywords: Organizational Citizenship Behavior (OCB), Counterproductive Work Behavior (CWB), Performance, Pakistan

\section{Introduction}

Performance is one of major concern in every organization; one may say that performance improvement is a super objective amongst any organization's objectives. There may be two areas related to performance in an organization, firstly Organizational Citizenship Behavior (OCB) and secondly Counterproductive Work Behavior (CWB). Many researchers have taken CWB and OCB as separate constructs but Kelloway et al, (2002) argue that these two dimensions simply reflect the opposite ends of the same continuum, namely Role Performance within the Organization; which means the concept of treating CWB and OCB as related, is fairly infant. Among these prior mentioned behaviors the former is constructive and plays its role in the development of organization, where as the latter leads to the decline of the organization; as the name suggests - it results in negative performance and not in positive or even no performance.

Turnipseed \& Rassuli (2005) define OCB as defending the organization when it is criticized or urging peers to invest in the organization; which means that OCB is 'going beyond the call of duty'. Theoretically, OCB typically refers to behaviors that positively impact the organization or its members (Poncheri, 2006), and can also be defined as per Joirman et al, (2006) a behavior that exceeds the routine expectations. This behavior may be different for different people as every employee in an organization perceives job requirements differently i.e. for some employees, helping others (Altruism) may be a routine, yet still, some will count it as beyond the scope of job requisites. A person who engages in OCB might receive appreciation and recognition that includes positive emotion and a greater likelihood of repeating the OCB (Miles et al, 2002).

CPBs (Counter Productive Behaviors) represent a class of behaviors that are discretionary. That is, individuals make conscious choices about whether to engage in behaviors such as playing mean pranks, swearing at coworkers, falsifying expense reports, and sabotaging the work of others (Mount et al, 2006). Interestingly there exists no difference of opinion among the researchers, regarding the relationship between OCB and CWB are concerned. Counterproductive Work Behavior (CWB) can be defined as a conduct that is averse to OCB, as per the findings of Spector and Fox (2002) OCB and CWB have opposite directions. Also the findings of Dalal (2005) purports; the relationships between an OCB facet and a CWB facet were also in the low to modestly negative range. The strength of facet relationships did not increase appreciably when OCB and CWB facets under consideration were directed toward the same target; which 
means that CWB is any behavior that will result in conflicting outcomes discussed in case of OCB. Moreover, correlational analyses revealed a moderate negative relationship between aggregate OCB and aggregate CWB (-.39, corrected for error of measurement), supporting the notion that OCB and CWB, although negatively correlated, are distinct constructs (Sackett, 2006).

The reason for choosing the current constructs for research purpose is their straight impact on performance, as study on these behaviors may lead to the reasons for poor performance which sequentially will make possible for us to weed out those reasons or rectify them in order to achieve required outcomes. Also this area lacks some considerable attention as not much work is done in this field, and if at all some work is done, it has been in different geographical context and not in presently chosen region i.e. Pakistan. The study is conducted in the public sector companies in Pakistan. The reason of selecting this sector is that; we observed that both constructs i.e. OCB \& CWB existed among the employees of the prior stated sector. The top management is very much satisfied due to high salary packages, good incentives and higher growth opportunities, but many amongst the blue collars (field workers) are not satisfied, due to hefty job hassles; this dissatisfaction is conveyed in the form of Counterproductive Work Behavior. So there is a need to address this issue and it is expected that this research will serve as a step in addressing this matter and will ultimately lead in the diagnosis and solution of the underlying problems.

\section{Literature review}

\subsection{Organizational Citizenship Behavior (OCB)}

Jacqueline et al, (2004) suggests that, individuals engage in OCB as a form of reciprocity based on organizational treatment. Also the study of Turnipseed \& Rassuli (2005) depicted that, the 'best' performing workers produced the strongest link between performance and functional participation, which is a helping-type (Altruism) OCB. Also Todd (2003) maintains that, OCB should have a particular impact on the overall effectiveness of organizations by adding to the social framework of the work environment. Employee attitudes were found to influence subsequent organizational citizenship. Indeed, as citizenship appears to consist of discretionary behaviors, how the employee perceives the organization (as evidenced by his/her attitude toward it) would likely predispose this employee to either perform or withhold such performance (Dick et al, 2006). Results indicate that perceptions of citizenship performance predict overall performance equally well across all task performance levels (Coole, 2003). As per Jacqueline et al, (2004), it is any behavior not officially required by the organization; rather its practice depends solely on the consent of employee as a consequence of the organizational environment. Deckop et al, (1999) argues in his study that, for employees low in value commitment, a pay-for-performance system appears to be a disincentive for engaging in OCB. Niehoff \& Yen (2004) asserts that, the belief among theorists is that as more employees engage in OCB, the organization becomes more successful. Such behavior (i.e. Organizational Citizenship Behavior) might enhance coworkers' or supervisors' productivity, help coordinate activities, increase the stability of organizational performance, and help the organization attract and retain employees (Borman, 2004). Gautam et al, (2005) maintains that citizenship behavior within an organization may vary, with change in geographic context i.e. OCB is enacted differently in different cultural contexts that what it means to be a 'good citizen' may vary. OCB is a function of how employees define in-role and extra-role job behavior (Morrison, 1994); i.e. which jobs, employees perceive as their duty and what beyond it. As per MacKenzie et al, (1993) findings, assuming that OCB prove to be helpful to the organization; managers must consider what they can do to foster them. After all prior discussed arguments there also exists a view regarding OCB i.e. OCB is an extra-role behavior that is not formally evaluated (Pond et al, 1997). This view is also shared by Diapola, Tarter \& Hoy, (2004) as their study proves that, Organizational Citizenship is discretionary; such behavior is its own reward; which means that it's up to the employees whether or not they want to indulge themselves in Organizational Citizenship Behavior.

\subsection{Counterproductive Work Behavior (CWB)}

In order to understand the concept of CWB, the comparative statement of Dalal (2005), on CWB against OCB could be taken into account i.e. OCB and CWB could be considered opposites in the sense that the former benefits the organization, whereas the latter harms it. The findings of Baker (2005) yield a supporting platform for the prior argument i.e. OCB and CWB (Counterproductive Work Behavior) were significantly negatively correlated; which means that a person high on OCB scale will not demonstrate any such behavior posing an adverse consequence to production and will perform for the promotion of the organization. The study of Sackett et al, (2006) yield that, Although aggregate OCB was predicted by Agreeableness, Openness, Extraversion, and Conscientiousness, aggregate CWB had modest and negative relationships with Openness and Extraversion, and was strongly negatively predicted by Conscientiousness, Emotional Stability, and Agreeableness. As per Miles et al, (2002) Negative perceptions of work environment relate to negative emotions, which are positively correlated with the occurrence of CWB. Spector \& Fox (2002) also seconds the prior discussed view i.e. Negative emotions are associated with CWB, whereas positive emotions are associated with OCB. Situations seen by people as unfair are stressors that may lead to negative emotions and presumably to subsequent strains beyond CWB (Fox, Spector \& Miles, 2001). Also, the findings suggest, for 
instance, that the successful elimination of high-CWB employees during the applicant screening process may not, in and of itself, simultaneously achieve the successful selection of high-OCB employees (Dalal, 2005). Throwing together production deviance, sabotage, theft, and withdrawal may give the false impression that all four forms of CWB relate to the same stressors and strains (Spector et al, 2006); which means that different stressors yield different counterproductive work behaviors. Also CWB is typically hidden and is committed by individuals at their own discretion (Spector \& Fox, 2002). In general, organizational stressors (such as constraints and injustice) were more closely associated with organizational than personal types of CWB, and interpersonal conflict was more closely associated with personal than organizational CWB (Fox, Spector \& Miles, 2001). The research by Posthuma et al, (2005) yields that, marginal temps (i.e. Temporary Workers) had lower job performance, and exhibited more counterproductive behaviors. The study of Flaherty \& Moss, (2007) asserts organizational justice to be a mediator of CWB, as it suggests that individuals who perceived their own workgroup to receive more justice than other units engaged in less counterproductive work behavior. Also, Mount et al, (2006) found that, personality influences job satisfaction, which in turn, has an effect on CPBs (Counter Productive Behaviors). Also the study of Deshpande et al, (2005) found that, respondents with high EI (i.e. Emotional Intelligence) perceived counter productive behaviors to be more unethical than those with low EI. This suggests that people with high EI tend to be better corporate citizens and that better ethical attitudes towards their firm and work. In a nutshell, Kelloway et al, (2002) suggests CPBs (Counter Productive Behaviors) and OCBs (Organizational Citizenship Behaviors) are negatively correlated.

$\mathbf{H}_{1}$ : after a comprehensive literature review on the relationship of $O C B$ and $C W B$ we can argue that CWB will prove negative correlation with $O C B$.

\section{Theoretical framework}

\section{Refer to Figure 1 (Appendix I)}

The theoretical framework is the graphical summary of the entire literature review. We can also say that the theoretical framework discusses the relationship among the variable(s) (i.e. CWB) that are deemed to be integral to the dynamics of situation being investigated. The above diagram depicts the relationship between Organizational Citizenship Behavior (OCB) and Counterproductive Work Behavior (CWB); it will help us to test the prior generated postulate and certain relationships and will improve our understanding of the dynamics of the situation.

\section{Participants, measures \& methodology}

\subsection{Participants}

The participant population for the study comprised of different companies working in the public sector of the country, particularly the banking and insurance sector. A systematic sampling procedure was first used to select the random company out of which the individual respondents were chosen through a simple random sampling procedure.

The total distributed questionnaires among the individuals were 275, out of which 221 responses were received. The high turnover of almost $80 \%$ can be attributed to the involvement of the respondents, in an issue which is closely related to their performance level and perhaps the motivation too. The unit of analysis was the individuals who responded to the survey.

\subsection{Measures}

In our survey, responses were rated on the Likert-scale format, with answers ranging from 1 to $5(1=$ never and $5=$ always). To measure Organizational Citizenship Behavior (OCB); we used OCB measure developed by Motowidlo \& Van Scotter (1994) and Lee \& Allen (2002). The measure developed by Bennett \& Robinson (2002), was chosen to determine and scale the Counter Productive Behavior (CWB), among the respondents.

The respondents were assured of confidentiality to guarantee the fairness of responses. To avoid any oversight due to a non-serious attitude we tried to utilize the time off of employees to fill the questionnaires. Also the respondents were provided with full explanation of the questionnaire.

\subsection{Methodology}

Following the collection of data, all the data received in the form of individual responses, was punched and a set of analyses were applied, to investigate the hypothesized, inverse relationship between OCB and CWB, their level of impact (significance), along with the direction of the relationship (if any).

\section{Results}

\subsection{Demographics}

The subsequent diagram depicts the demographical data distribution, pertaining to the respondents on the basis of age, education and gender.

\section{Refer to Figure 2 (Appendix I)}


The third column shows the number of respondents falling under the criteria and description mentioned in the first and second column respectively, and based on the frequency, the fourth column yields the percentage of respondents falling under the relative description (criterion) mentioned.

The careful analyses of the above tabulation suggests that most of the respondents were young (16-24), were reasonably educated i.e. graduates; but as far as gender categorization is concerned, we observe that there is no mark difference between the percentages of male and female workers, this may be due to recent delineation from the trend of not allowing females to work.

\subsection{Correlation Analyses}

\section{Refer to Figure 3 (Appendix I)}

The above mentioned value for correlation is proving the hypothesis to be true, still it differs from the value obtained after research by the western researchers, as results achieved by Dalal (2005) ranged from $-0.33^{* *}$ to $-0.11^{* *}$ between OCB-I, OCB-O and CWB-I, CWB-O. The results of Miles et al, (2002) are also aligned with those of Dalal (2005) i.e. $-0.11^{* *}$. The reasons for this variation are explained in the sections to follow.

\subsection{Regression Analysis}

\section{Refer to Figure 4a (Appendix I) \\ Refer to Figure 4b (Appendix I)}

The regression analyses reveal that CWB accounts for almost 55\% of the total variation in OCB, which means that all the factors that contribute to the increment in CWB also have their role in the diminishing of OCB. Although the results are unexpected and quiet surprising for the researchers, as this value was anticipated to be less than the currently achieved one.

\section{Discussion}

After all the aforementioned statistics, we can easily concede that OCB and CWB are negatively related to each other hence proving the worth of our hypothesis. To the researchers expectations, the results found in the current geographical context are similar to those established by the western researchers but the strength found in our geographic context is more which can be explained using the following notion i.e. Pakistan is a developing country, the motivation level exists mostly on $1^{\text {st }}$ two levels of Maslow's hierarchy of need theory, that's why people strive for a job where they can get maximum salary, they usually don't bother about the working environment and like, due to this very reason people who are satisfied with their position at an organization have developed citizenship behavior over time, and the rest who have reservations on the manner, their organization treats them, have developed counterproductive work behavior (CWB).

As mentioned earlier, both the constructs chosen have a significant impact on the performance whether be it individual or organizational. Our study has yielded an inverse yet strong relationship between the chosen constructs as per the hypothesis. And it has been found that employees rating high on OCB scale are found to rate low on CWB scale. Interestingly employees projecting $\mathrm{OCB}$, also sometimes do tend to exhibit actions depicting CWB but that cannot be viewed as permanent virtue, as Counterproductive Work Behavior means the exhibition of counterproductive actions on a routine and permanent basis.

OCB is regarded as selfless behavior of employees towards the organization, this behavior can help the organization a long way towards progress, as an employee exhibiting this behavior can be expected to do anything under his/her power to benefit the organization. OCB can also be explained as the maximum an employee can give as a token of thanks to his/her organization.

CWB on the other hand is something which can become a worse nightmare for an organization's management, as employees demonstrating such behavior are not non-productive but are counter-productive, because they tend to play a role which altogether reverses the organization's progression. Mild examples of CWB identified in previous researches, could be littering the environment, cursing co-workers etc.

As some researchers have also treated OCB and CWB as two extremes of a continuum, we agree to this notion as OCB and CWB cannot co-exist in a given situation for a given employee, i.e. either the employee will project Citizenship Behavior or Counterproductive; because citizenship behavior is something which can be a resultant of the perception of the employee, as being fairly treated by the higher-ups or due to any sort of empathetic conduct by the peers; whereas counterproductive behavior can be consequential outcome of dissatisfaction among the employees due to the reasons mentioned earlier or actions that are considered by the employees as unfair and like, here one thing needs readers and analysts observation, that is an employee will project counterproductive behavior, if he/she feels being treated unfair, even if the organization is treating him/her well in reality, as results found by Spector \& Fox, (2002) purports CWB and OCB are the result of both employee and organization variables, and that they have many similar causes. This 
parallelism makes it useful to think about both as forms of voluntary response to organizational conditions that have emotional meaning for people. Which means it is primarily based upon the employees own personal judgment and perception regarding the organization.

\section{Conclusion}

The sole reason to conduct this study was to measure the relationship between Organizational Citizenship Behavior (OCB) and Counterproductive Work Behavior (CWB) and to explore for methods which can result in constructive behaviors in our case OCB and that may help us in avoiding destructive behaviors like CWB. As mentioned earlier the results are aligned with the western researches on these constructs.

A thorough analysis of the demographic data revealed that respondents' age has been observed to play its role in the study, as it has been experienced that elderly are more prone to display OCB. It has been found that the respondents who were well educated showed an inclination towards exhibiting OCB. Also it has been observed that the results from the male and female respondents are quiet alike, which suggests that gender has no affect, whatsoever, on the chosen constructs i.e. OCB and CWB.

Controlling the counterproductive behavior may result in harmonious and pleasant work environment as the friction between the management and employees will diminish, the employees work life will become rich and conducive for improved performance. As Spector \& Fox (2002) recommends that, from a practical perspective, the management of conditions that tend to induce a particular emotion can go a long way toward reducing CWB and enhancing OCB, and thereby improving both employee and organizational well-being.

Moreover, the management must also strive to retain and continue with the state of organizational citizenship, as it results in improved performance, which is advantageous and helpful to both the workforce and the organization, resulting in swift achievement of objectives by the organization and hence a better work-life for the employees.

\section{Limitations}

As stated previously in the document, ours was a cross sectional study in which the respondents rated themselves, which may have an effect on the study due to the difference in perception regarding the questions included in the study, although a thorough elucidation was provided to the respondents who had confusion.

Secondly, there are chances of the contamination of data due to the self rating procedure, as incase of counterproductive work behavior, the respondents are usually expected to rate themselves low on CWB scale, even if they are assured of confidentiality.

Thirdly, as the results prove that about $55 \%$ of variation in OCB is accounted for the factors that also determine CWB, there still is room present for the subsequent researchers to determine the antecedents that account for the remaining $45 \%$ of the chosen dependant variable. Also as it has been found that age and education does mediate the relationship, it is advised for the upcoming researchers to include tenure in their demographic analyses which is expected to play some role in the determining of the chosen variables.

The fourth and final limitation is related to the modest number of respondents, as this study was affected by lack of resources, the sample may not be a complete representative of the population. Apart from the 'lack of resources' factor, the employees of the chosen sector have much to do with the current size of the sample, as many of them were hesitant and apprehensive about the 'self perceived' consequences incase of their self rating on CWB scale (discussed previously in second limitation).

\section{References}

Baker, B.A. (2005). The Good, The Bad And The Ugly: The Mediating Role of Attributional Style In The Relationship Between Personality and Performance. North Carolina State University.

Borman, W.C. (2004). The Concept of Organizational Citizenship. Personnel Decisions Research Institutes, Inc., Tampa, Florida, and University Of South Florida.

Coole, D. R. (2003). The Effects of Citizenship Performance, Task Performance, and Rating Format on Performance Judgments. College Of Arts And Sciences, University of South Florida.

Dalal, S. R. (2005). A Meta-Analysis of the Relationship Between Organizational Citizenship Behavior And Counterproductive Work Behavior. Journal of Applied Psychology, Vol. 90, No. 6, 1241-1255.

Deckop, R. J., Mangel, R., \& Cirka, C. C. (1999). Getting More Than You Pay For: Organization Citizenship Behavior And Pay For Performance Plan. Academy Of Management Journal, Vol, 42, No. 4. Pp. 420-428.

Deshpande, Et Al. (2005). The Impact of Emotional Intelligence on Counterproductive Behavior In China. Management Research News, Vol. 28, No. 5.

Diapola, M. F., Tarter, C. J., Hoy, W. K. (2004). Measuring Organizational Citizenship of Schools: The Ocb Scale. 
Dick, R., Grojean, M., Christ, O \& Wieseke, J. (2006). Identity and the Extra Mile: Relationships Between Organizational Identification And Organizational Citizenship Behaviour. British Journal of Management, Vol. 17, 283-301.

Flaherty, S., and Moss, S.A. (2007). The Impact of Personality and Team Context On The Relationship Between Workplace Injustice And Counterproductive Work Behavior. Journal of Applied Social Psychology, 37, 11, pp. 2549-2575.

Fox, S., Spector, E. P., \& Miles, D. (2001). Counterproductive Work Behavior (Cwb) In Response to Job Stressors And Organizational Justice: Some Mediator And Moderator Tests For Autonomy And Emotions. Journal of Vocational Behavior, 59, 291-309.

Gautam, Et Al. (2005). Organizational Citizenship Behavior and Organizational Commitment in Nepal. Asian Journal of Social Psychology, 8: 305-314.

Jacqueline A-M., Shapiro, C., Kessler, I., and Purcell, J. (2004). Exploring Organizationally Directed Citizenship Behavior: Reciprocity or 'It'S My Job'? Journal of Management Studies, 41:1, 0022-2380.

Joireman, J., Daniels, D., Falvy, J., \& Kamdar, D. (2006). Organizational Citizenship Behavior As Function Of Empathy Consideration Of Future Consequences, And Employee Time Horizon: An Initial Exploration Using An In-Basket Simulation Of Ocbs. Journal of Applied Social Psychology, 36, 9, pp. 2266-2292.

Kelloway, E. K., Loughlin, C., Barling, J., \& Nault, A. (2002). Self Reported Counter Productive Behavior And Organizational Citizenship Behaviors: Separate But Related Constructs. International Journal of Selection and Assessment, Vol. 10, No. $1 / 2$.

Mackenzie, S. B., Podsakoff, P. M., \& Fetter, R. (1993). The Impact of Organizational Citizenship Behavior on Evaluations of Salesperson Performance. Journal of Marketing, Vol. 57, 70-80.

Miles, Et Al, (2002). Building An Integrative Model Of Extra Role Work Behavior With Organizational Citizenship Behavior. International Journal Of Selection And Assessment, Vol.10, No. 1/2.

Morrison, E. W. (1994). Role Definitions And Organizational Citizenship Behavior: The Importance of The Employee's Perspective. Academy Of Management Journal, Vol. 37, No. 6, 1543-1567.

Mount, M., Ilies, R., Johnson, E. (2006). Relationship of Personality Traits and Counterproductive Work Behaviors: The Mediating Effects of Job Satisfaction. Personnel Psychology, 59, 591-622.

Poncheri, R.M. (2006). The Impact of Work Context on the Prediction of Job Performance. North Carolina State University.

Pond, S., Nacoste, R., Mohr, M., \& Rodriguez, C. (1997). The Measurement of Organizational Citizenship Behavior: Are We Assuming Too Much? Journal of Applied Social Psychology, 27, 17, pp. 1527-1544.

Posthuma, R. A., Campion, M.A., And Vargas, A. L. (2005). Predicting Counterproductive Performance Among Temporary Workers: A Note. Industrial Relations, Vol. 44. No. 3.

Sackett, Et Al, (2006). Citizenship and Counterproductive Behavior: Clarifying Relations between the Two Domains. Human Performance, 19(4), 441-464.

Spector, P. E., Fox, S. (2002). An Emotion-Centered Model of Voluntary Work Behavior, Some Parallels Between Counterproductive Work Behavior And Organizational Citizenship Behavior. Human Resource Management Review, $12,269-292$.

Todd, S. Y. (2003). A Causal Model Depicting The Influence of Selected Task and Employee Variables On Organizational Citizenship Behavior. The Florida State University College of Education.

Turnipseed, D. L., and Rassuli, A. (2005). Performance Perceptions of Organizational Citizenship Behaviours At Work: A Bi-Level Study Among Managers And Employees. British Journal of Management, Vol. 16, 231-244.

Yen, H. R., Niehoff, B. P. (2004). Organizational Citizenship Behaviors and Organizational Effectiveness: Examining Relationships In Taiwanese Banks. Journal of Applied Social Psychology, 34, 8, pp. 1617-1637.

\section{Appendix I}

Counterproductive Work Behavior
Organizational Citizenship

Behavior

Figure 1. Theoretical Framework 


\begin{tabular}{|c|c|c|c|}
\hline \multicolumn{2}{|c|}{ Criteria (Description) } & \multirow{2}{*}{$\begin{array}{c}\text { Frequency } \\
187\end{array}$} & \multirow{2}{*}{$\begin{array}{l}\% \\
85\end{array}$} \\
\hline \multirow{3}{*}{ Age } & $16-24$ & & \\
\hline & $25-33$ & 29 & 13 \\
\hline & 43-above & 5 & 2 \\
\hline \multirow{3}{*}{ Education } & Undergraduates & 60 & 27 \\
\hline & Graduate & 111 & 50 \\
\hline & Masters & 50 & 23 \\
\hline \multirow{2}{*}{ Gender } & Male & 118 & 53 \\
\hline & Female & 103 & 47 \\
\hline
\end{tabular}

Figure 2. Demographical data

\begin{tabular}{|c|c|c|c|c|}
\hline \multirow{2}{*}{ Mean } & \multirow{2}{*}{ S.D. } & \multicolumn{2}{|c|}{ Pearson Correlation } \\
\cline { 3 - 5 } OCB & 3.9397 & .24214 & OCB & CWB \\
\hline CWB & 1.5084 & .14365 & $-.742(* *)$ \\
\hline
\end{tabular}

Figure 3. Descriptive and Correlation Analyses

** Correlation is significant at the 0.01 level (2-tailed).

${ }^{\mathrm{A}}$ Number of Respondents $=221$

\begin{tabular}{|c|c|c|c|c|}
\hline \multirow{2}{*}{ Model } & Predictors & Beta & t & Sig. \\
\hline \multirow{2}{*}{1} & OCB (Constant) & - & 50.317 & .000 \\
\cline { 2 - 5 } & CWB & -.742 & -16.361 & .000 \\
\hline
\end{tabular}

Figure 4a. Regression Model

a) Dependent Variable: OCB

\section{R square: .550 \\ F: 267.679}

Adjusted R square: .548

Significance: .000

Number of Respondents: $\mathbf{N}=221$

Figure 4b. Regression Model

a) Predictors: OCB (Constant), CWB 


\section{Appendix II}

\section{Questionnaire}

Biographical Characteristics (Section I)

1. Age: years

2. Gender: Male/ Female

3. Qualification: (Highest)

\section{Organizational Citizenship Behavior (Section II)}

(C) Lee and Allen (2002) \& (C Motowidlo and Van Scotter (1994)

4. Adjusted your work schedule to accommodate other employees' requests for time off.

5. Helped others who have been absent.

6. Showed genuine concern and courtesy toward coworkers, even under the most trying business or personal situations.

7. Offered ideas to improve the functioning of the organization.

8. Expressed loyalty toward the organization.

9. Taken action to protect the organization from potential problems.

10. Demonstrated concern about the image of the organization.

11. Took the initiative to troubleshoot and solve technical problems before requesting help from a supervisor.

12. Voluntarily did more than the job requires so that I can help others or contribute to the overall functioning of the facility.

\section{Counterproductive Work Behavior (Section III)}

(C) Bennett and Robinson (2002)

13. Taken an additional or a longer break than is acceptable at your workplace.

14. Come in late to work without permission.

15. Littered your work environment.

16. Cursed at someone at work.

17. Called in sick when you were not.

18. Lost your temper while at work.

19. Neglected to follow your boss's instructions.

20. Left work early without permission.

21. Left your work for someone else to finish.

22. Acted rudely toward someone at work.

23. Put little effort into your work.

\section{Likert Scale used}

\begin{tabular}{|c|c|c|c|c|}
\hline Never & Seldom & Sometimes & Often & Always \\
\hline 1 & 2 & 3 & 4 & 5 \\
\hline
\end{tabular}

